\title{
1 Self-calibration technique for on-machine 2 spindle-mounted vision systems
}

\author{
3 Alberto Mendikute ${ }^{1, *}$, Ibai Leizea ${ }^{1}$, José A. Yagüe-Fabra ${ }^{2}$ and Mikel Zatarain ${ }^{1}$ \\ $4 \quad 1$ IK4-Ideko; amendikute@ideko.es \\ 52 I3A, Universidad de Zaragoza; jyague@unizar.es \\ 6 * Correspondence: amendikute@ideko.es; Tel.: +34 943748000
}

\begin{abstract}
On-machine measuring (OMM) systems are being more and more applied in machine tools in order to measure workpieces on the machine itself. Many of these systems are directly mounted in the machine spindle, so the measuring uncertainty is affected by clamping positioning and orientation variations, especially when integrating optical systems based on machine vision. This paper presents a self-calibration technique for vision systems by using redundant information of on machine measurements, avoiding extra mechanical anchoring or calibration means. It has been applied to a vision system with the angular placement uncertainty of a tool holder coupling being the main uncertainty contributor. A milling machine pilot case has been selected for demonstration, showing an effective self-calibration capability both in laboratory and industrial conditions.
\end{abstract}

Keywords: Machine tool; Measuring; Uncertainty

\section{Introduction}

In the last years, due to the growth of sectors as aeronautics, energy generation, etc., an increasing need for manufacturing of large parts has been raised. This leads to new challenges regarding the design of manufacturing systems able to meet new requirements [1], including the development of new machine concepts. In addition, the efficient and effective verification of these large parts has also become a key issue.

Smaller parts are usually verified by using Coordinate Measuring Machines (CMM) when a tight measurement uncertainty is required. However, for these large parts, a large scale CMM is seldom available. Besides, taking the part out of the machine tool, preparing it at the CMM and correcting the possible errors back in the machine tool is a very time consuming process. Optical measurement systems such as laser trackers are an alternative in this case [2]. However, the resulting uncertainty, the cost of the system, the measurement time and the accessibility to the part are still an issue.

For these reasons the use of dimensional measurement systems directly integrated in the machine tool; i.e., on machine measurement (OMM) systems for the part [3]; is a relatively recent technology that helps to avoid most of the mentioned problems. These systems allow the integration of manufacturing and verification under the same boundary conditions, which speeds up the process at a relatively low cost.

However, it should be borne in mind that OMM cannot identify all the possible errors of large parts, since systematic errors of the machine itself will cause the repetition of the machining error during the verification process, and will not be detected [4]. The most influential errors in large machines are the static errors $[5,6]$ together with the thermo-mechanical errors [7]. This makes their compensation a key factor in large machines in order to obtain the required accuracy. In this context, an on-machine verification system allows both the detection of tool wearing effects and thermal and inertial deformations of the part caused by the large masses and machining time needed. In addition, on machine measurement allows a quick and more frequent dimensional verification of the workpiece and an immediate correction of the errors found, decreasing the probability of dismissing these very expensive parts. 
Among the systems used for on machine verification of parts, touch probing is one of the most classic ones [5, 8]. On the other hand, optical inspection based on cameras is becoming more and more frequent due to its measurement speed and its more and more improved measurement uncertainty [3]. For the case of touch probing, the system is not sensitive to errors in location of the probe on the headstock, as long as rotational axes are not used during the inspection $[9,10]$. On the contrary, optical measurement based on cameras mounted directly in the spindle always needs a good knowledge of the situation and orientation of the measuring systems. For that, the calibration of the system is almost unavoidable. A possible solution to avoid it is the use of on purpose developed interfaces between the optical probe and the machine spindle, which can be very repetitive. However, most of the times, the tool holder itself (ISO, HSK ... taper) is directly used for it due to the simplicity and availability of that solution.

It is well known that the most classic taper solutions (ISO, BTS ...) are prone to location errors, especially when they have been used for some time and may present some wear [11]. The HSK taper was developed to avoid some issues found with the classical tapers, mainly with high speed interface deformation in mind, but at the same time obtaining much better static repeatability results [12]. However, the angular orientation of the tool, or of the OMM system in this case, with respect to the spindle axis (C-axis) may present high uncertainties - in the order of several degrees - due to the backlashes of the kinematic chain from the motor to the main spindle [13]. This angular error makes necessary the calibration of the optical system even when HSK tapers are being used. In order to compensate for such clamping uncertainty, recent developments appeared in the market for $6 \mathrm{D}$ on-machine calibration of OMMs in machine tool and robotic applications [14] by using infrared sensors but with limitations in the field of work and not directly attached to the spindle.

(a)

\section{Out-of-machine}
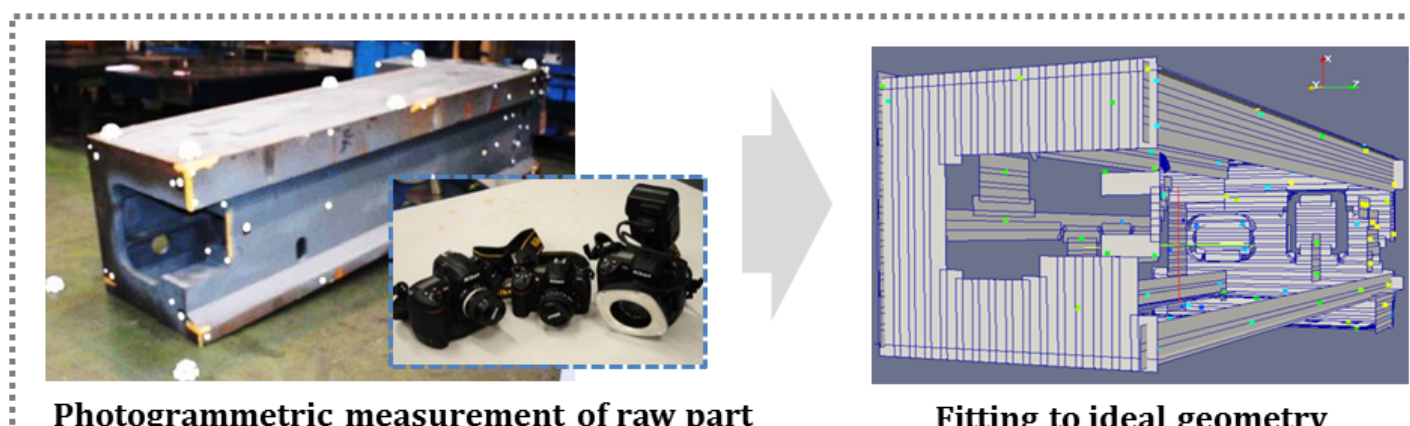

Fitting to ideal geometry

Optimal raw part location and orientation

On-machine

(b)

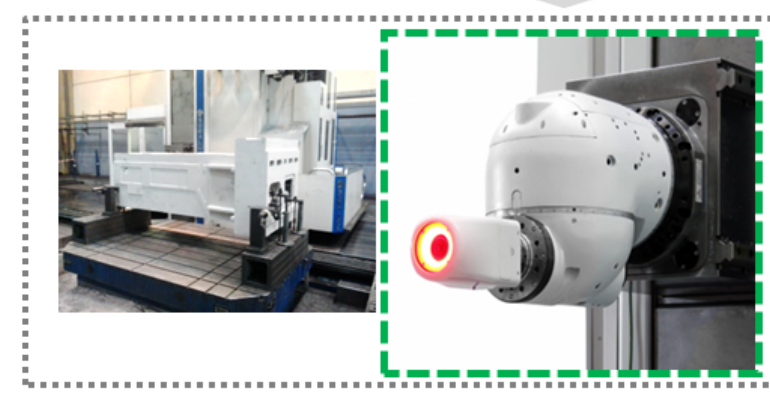

(ideal par frame, $\boldsymbol{O} \boldsymbol{p}$ )

OMM of reference targets and resolution of raw part location and orientation (machine frame, $\mathbf{O m}$ )

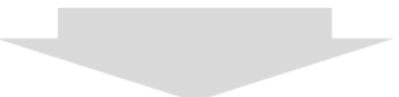

Deviation calculation and fixturing correction

Figure 1. Vision OMM system for raw part alignment in milling. (a) Out-of-machine raw part measurement by portable photogrammetry and fitting to ideal CAD geometry. (b) On machine stereo-photogrammetric vision system for raw part location and orientation measurement.

The development shown in this paper is a step forward for precise operation of on machine measuring systems based on machine vision. It has been applied to a portable vision OMM system for the alignment of large raw parts in milling machines (Figure 1), coupled by an ISO taper into the 
milling machine spindle (Figure 2). A self-calibration technique is presented by using redundant information of on-machine measurements of the part by machine vision. A similar problem has been addressed in previous works for different applications of active vision systems such those mounted on robots [15,16], unmanned aerial vehicles [17,18], augmented reality [19], etc. The technique here presented has been specifically optimized for a machine-tool application. Hence, the proposed self-calibration method is based on redundant information given by a set of multiple camera views taken by the OMM on the raw part from known CNC machine coordinates. It allows the compensation of the coupling orientation error around the C-axis, which is the most important error source in the location of the OMM system in the machine. This avoids extra mechanical anchoring or calibration means for its precise operation every time the optical system is coupled into the spindle.

The vision OMM system is introduced under the scope of the raw part alignment solution in Section 2. In Section 3 the measuring geometry of the OMM is described. Eventually, in Section 4, the experimental validation on industrial applications and the repeatability results are presented demonstrating its self-calibration capability.

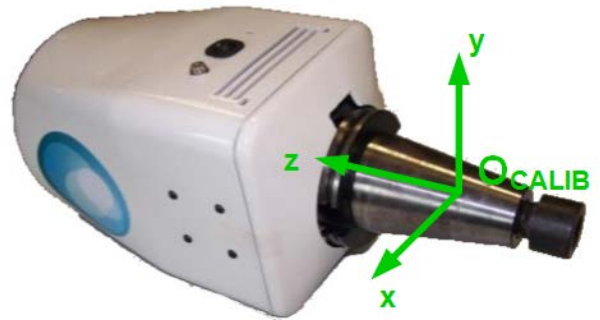

(a)

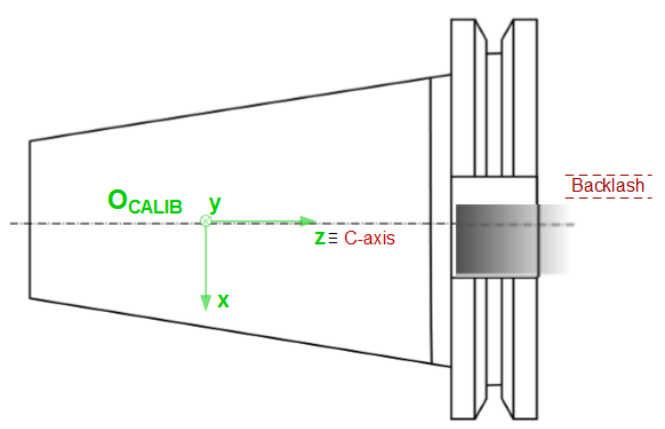

(c)

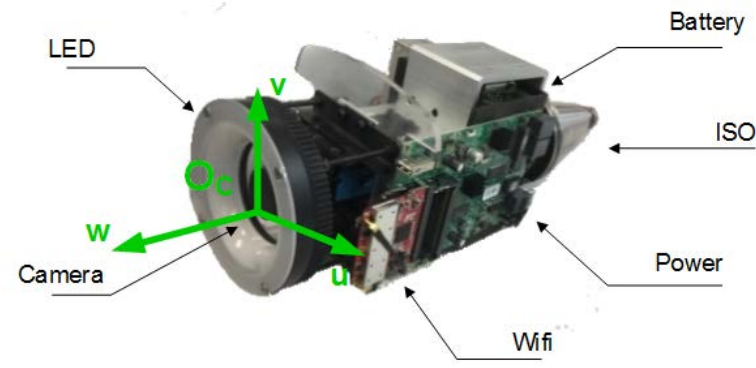

(b)

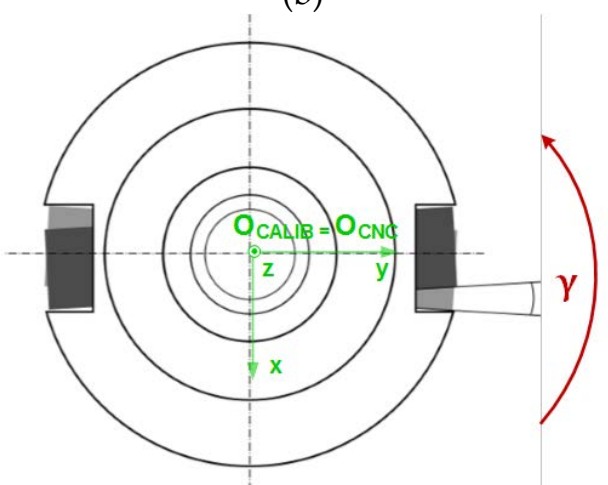

(d)

Figure 2. Portable OMM vision system with ISO coupling and positioning backlash $\gamma_{s}$ around the spindle C-axis. (a) Reference system of the vision OMM system, OCALIB, joined to the taper. (b) Camera reference frame, Oc, placed at the principal point. (c) Detail of the OMM system reference frame on the taper. (d) Schematic view of the coupling backlash, $\gamma_{s}$, between the OMM system frame and the spindle frame, OCNC.

\section{Materials and Methods}

Large raw parts require a time consuming in machine alignment process prior to the machining itself. With the aim of reducing it, a solution was developed in a previous work [3] based on two machine vision systems: the first one for the raw part characterization, by means of out-of-machine photogrammetry; and the second one, the pilot case under study in this paper (Figure 1); i.e., an OMM system to determine the raw part location and orientation with a milling-machine spindle-integrated portable vision system. Initially, with the out-of-machine photogrammetric system (Figure 1a), the raw part is measured by using retroreflective coded and non-coded optical targets. Images are taken around the part (a Nikon D300S, 3Mpixel, $24 \mathrm{~mm}$ camera is used) and the photogrammetry system calculates target 3D coordinates. Non-coded targets are used to measure 
the raw part surfaces. Coded targets are properly located as later references for the second system, the on-machine vision system.

Non-coded targets characterizing raw part surfaces are then fitted to the ideal part surfaces to be obtained after machining. The ideal geometry and the fitting reference frame are given by a CAD file (Figure 1a). Fitting algorithms play an important role in coordinate metrology [20-22]. In this work, positive and even overstock distribution is assumed as the fitting criteria [3]. As a result, the measuring frame is properly aligned to the ideal part frame, and corresponding 3D optimal coordinates of the coded references are determined in the ideal part frame. Once the optimum raw part setup is determined, the on-machine measuring system proceeds (Figure 1b). A single camera stereo-photogrammetric OMM solution (Imaging Source DMK 23GP031, 5Mpixel, $2592 \times 1944$ format, $2.2 \mu \mathrm{m}$ pixel size, $6 \mathrm{~mm}$ focal distance) is adopted for measuring the reference targets (Figure $2 a)$, determining the ideal part frame location and orientation with respect to the machine frame. If large deviations are observed, fixturing corrections are performed in order to properly align the raw part prior to its machining. The portable vision system is installed in the milling machine spindle by an ISO50 coupling (DIN 69871). Figure $2 \mathrm{~b}$ shows a schematic view of the evaluated coupling backlash around the spindle C-axis. For the pilot case under study, orientation backlash ranged at $6.15 \mathrm{~mm} / \mathrm{m}(0.35 \mathrm{deg})$ according to nominal coordinates. As a result, every time the portable system was installed into the spindle, a time-consuming calibration procedure was required in the machine in order to compensate for coupling variations and enabling precise on-machine measuring.

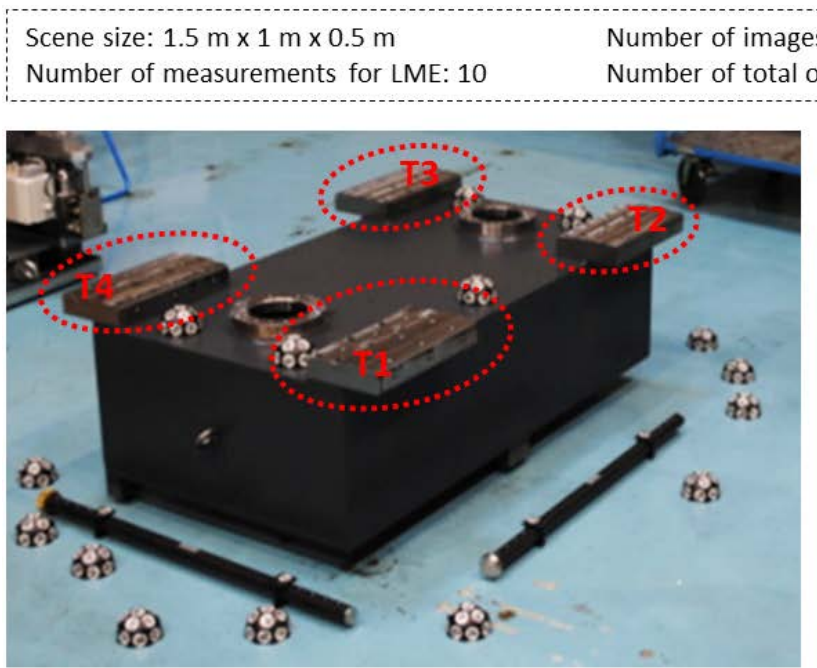

(a)

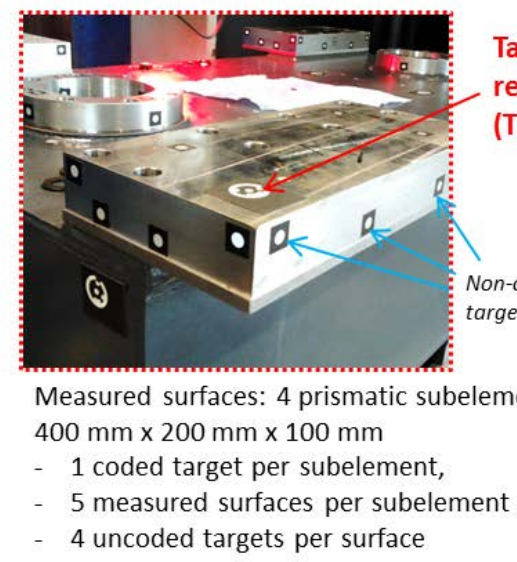

(b)

Figure 3. Reference part for the OMM system self-calibration evaluation. (a) Out-of-machine measurement of 4 prismatic sub-elements (T1 to T4) on the test part, showing scale bars and auxiliary coded targets for portable photogrammetry. (b) T1 prismatic sub-element showing both non coded targets in milled surfaces for evaluation and a reference coded target for on-machine part alignment.

In order to overcome this limitation, a self-calibration approach has been developed based on stereo-photogrammetry. A redundant measuring strategy of reference targets with known 3D optimal coordinates $\left(X_{i}\right.$ given by portable photogrammetry, see Section 3.2) is conducted from a set of images taken from known CNC machine spindle location and orientations $\left(d_{c n c}\right.$ and $R_{c n c}$ in Section 3.3), enabling the simultaneous resolution of the raw part location and orientation $\left(\mathrm{d}_{\mathrm{P}}\right.$ and $R_{P}$ in Section 3.2) in machine coordinates, along with the C-axis coupling orientation, $\gamma_{s}$, of the vision system.

A test part has been used in order to evaluate the performance of the developed self-calibration approach. It is formed by four prismatic steel sub-elements screwed to a mechano-welded structure and milled to a nominal geometry (Figure 3). Reference targets were placed at the corner of each prismatic sub-element, to a total of 4 targets (T1 to T4). Part geometry given by optical target 3D coordinates was measured by photogrammetry and fitted to the nominal CAD geometry. The test 
part was then located at a milling-machine and properly aligned to the machine axes to set it as the OMM performance evaluation reference.

In Section 3.1 the initial OMM calibration procedure performed in a CMM, needed only the first time the camera is going to be used and no longer required every time the OMM is clamped into the machine, is presented. Section 3.2 describes the on-machine multiple view geometry of the vision system used to solve the raw part location and orientation (6D) by stereo-photogrammetry, demonstrating the relevant influence of clamping backlash into test part measurement results. Accordingly, Section 3.3 describes how the self-calibration of the tool holder clamping error is integrated into the measuring chain (7D), enabling precise measurement of clamping backlash angle $\left(\gamma_{s}\right)$ along with raw part 6D. Section 4 presents the resulting joint uncertainty performance for the whole system, including both out-of-machine and on-machine vision systems for raw part alignment, along with evaluation results in an industrial scenario. Finally, Section 5 brings main conclusions of the presented work.

\section{Machine Vision OMM for raw part alignment}

\subsection{OMM calibration}

A similar concept to Lu et.al [23] was adopted in the milling machine for calibrating the OMM system camera model extrinsic parameters (Oc camera principal frame) into the ISO taper reference frame used $\left(O_{C A L I B}\right)$, along with camera intrinsic parameters given by the focal distance and lens distortion model according to Brown [24]. Although the process provided precise calibration every time the system was clamped into the spindle to compensate for the taper coupling uncertainty, the process lasted up to 1 hour, limiting the industrial usability of the solution. Moreover, the calibration is affected by the precision of the machine. This makes errors to be propagated in the calibration and consequently to the measurement. In order to overcome the accuracy and time limitations, the process has been taken out of the machine and a Zeiss Prismo Navigator CMM is used instead. Both extrinsic and intrinsic camera parameters are solved simultaneously and the calibration is performed only once, independently of the machine to be used.

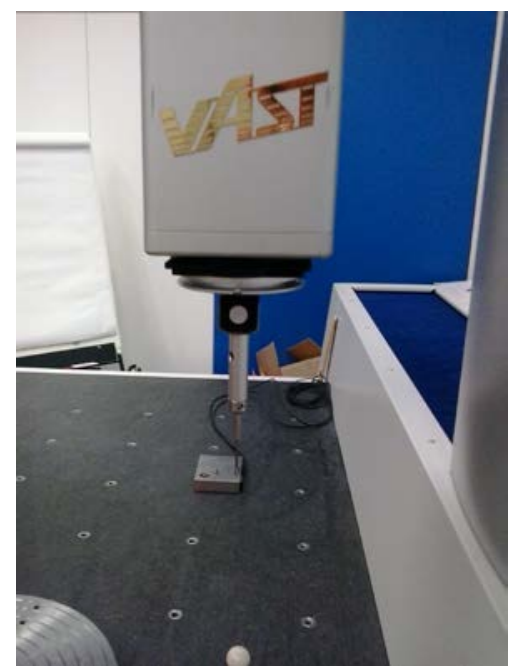

(a)

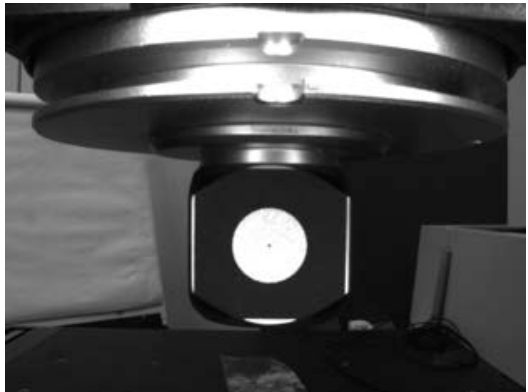

(b)

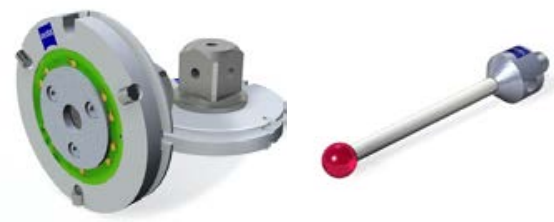

(c)

Figure 4. (a) ZEISS Prismo CMM probe head with integrated precalibrated cubic tip. (b) Retroreflective target on a surface of the tip. (c) Schematic view of the precalibrated tip and the adapter plate used (Courtesy of (C) Carl Zeiss).

The calibration process is based on generating a pyramidal grid structure where a single retroreflective target is captured in different images from different points of view. For this purpose, the CMM integrated target (Figure 4) is placed at different predefined spatial positions relative to the OMM reference frame (OСALIB) (Figure 5), which is properly probed to be referenced with respect to 
the CMM frame $\left(\mathrm{O}_{\mathrm{C} M M}\right)$. The system is solved through a set of $2 \mathrm{D}$ image points and their corresponding known 3D positions in the CMM frame (OСMM), following the same multivariable optimization strategy as for the reprojection problem described in Sections 3.2 and 3.3.

The target is precalibrated to the tip frame using a ZEISS O-Inspect optical CMM. This precalibration aims to know the 3D offset between the tip probe and the center of the target, so that a pre-defined calibration grid can be programmed at the CMM frame (Figure 5b) with an uncertainty ranging $0.001 \mathrm{~mm}$ all over the calibration grid volume.

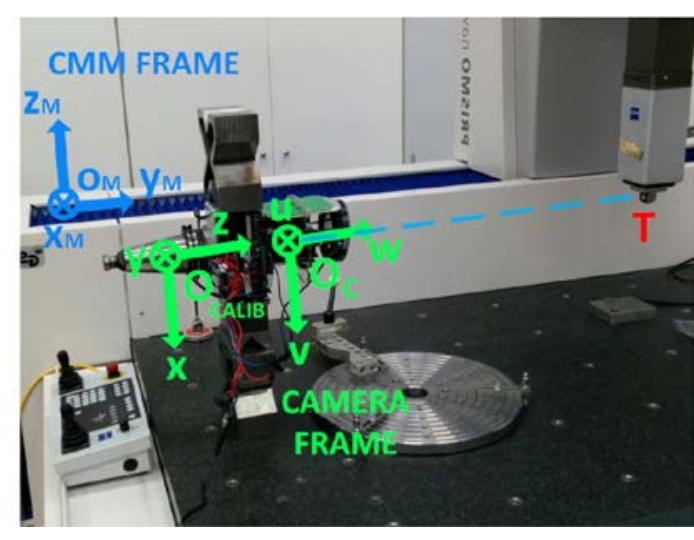

(a)

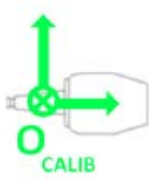

1

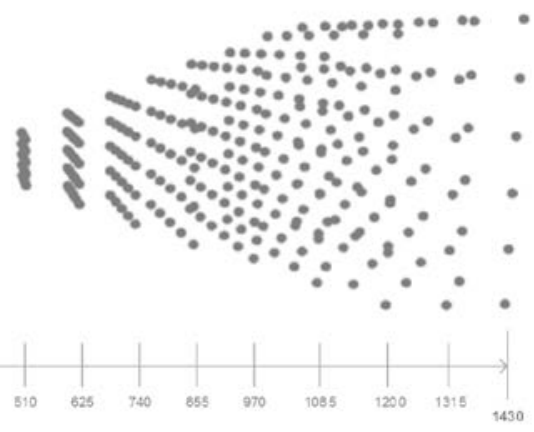

(b)

Figure 5. OMM calibration in a CMM. (a) Calibration layout into a Zeiss Prismo CMM. (b) Calibration grid with respect to the OMM frame at taper (OCALIB).

Calibration grid consists of planar dense point grids located at equidistant 10 positions along camera main axis, from a minimum distance of $395 \mathrm{~mm}$ to a maximum of $1430 \mathrm{~mm}$ (Figure 5b). As a result of all the above, the obtained calibration results are shown in Table 1:

Table 1. Camera calibration: extrinsic and intrinsic parameters.

\begin{tabular}{|c|c|c|c|c|c|c|c|}
\hline & $\begin{array}{c}f \\
(m m)\end{array}$ & $\begin{array}{c}c l_{0} \\
\text { (pixel) }\end{array}$ & $\begin{array}{c}r w_{0} \\
\text { (pixel) }\end{array}$ & $\begin{array}{c}k_{1} \\
\left(\text { pixel }^{-2}\right)\end{array}$ & $\begin{array}{c}k_{2} \\
\left(\text { pixel }^{-4}\right)\end{array}$ & $\begin{array}{c}\pi_{1} \\
\text { (pixel } \\
\end{array}$ & $\begin{array}{c}\pi_{2} \\
\left(\text { pixel }^{-1}\right)\end{array}$ \\
\hline \multirow[t]{2}{*}{ Intrinsic parameters } & 6.189 & -8.732 & 27.52 & $2.997 \mathrm{e}-08$ & $-1.937 \mathrm{e}-15$ & $-6.188 \mathrm{e}-08$ & $3.408 \mathrm{e}-07$ \\
\hline & $\begin{array}{c}d_{X} \\
(m m) \\
\end{array}$ & $\begin{array}{c}\boldsymbol{d}_{\boldsymbol{Y}} \\
(\mathrm{mm})\end{array}$ & $\begin{array}{c}\boldsymbol{d}_{\mathrm{Z}} \\
(\mathrm{mm})\end{array}$ & $\begin{array}{c}\alpha \\
(r a d)\end{array}$ & $\begin{array}{c}\beta \\
(r a d)\end{array}$ & $\begin{array}{c}\gamma \\
(r a d)\end{array}$ & \\
\hline Extrinsic parameters & -2.139 & 0.301 & $-3.203 e+02$ & -0.003 & -0.009 & 0.03 & \\
\hline
\end{tabular}

Being $\mathrm{f}$ the focal distance of the pin-hole projection model of the camera, $\mathrm{k}_{1}$ and $\mathrm{k}_{2}$ the radial distortion coefficients, $\pi_{1}$ and $\pi_{2}$ the tangential distortion coefficients, $\mathrm{cl}_{0}$ and $\mathrm{rw}_{0}$ the principal point decentering at the image plane, $\mathrm{dX}$, dy and $\mathrm{dz}$ the 3D camera frame coordinates to the taper frame, and $\alpha, \beta$ and $\gamma$ the Euler angles of the camera frame to the taper frame.

\subsection{OMM by stereo-photogrammetry}

Once the camera has been calibrated it can be attached to the spindle to carry out the on-machine measurement of the workpiece. Figure 6 shows the multiple view geometry of the on-machine vision system for measuring part location and orientation. It is defined as the translation $\left(d_{P}\right)$ and rotation $\left(R_{P}\right)$ of the ideal part frame $\left(O_{P}\right)$ with respect to machine frame $\left(O_{M}\right)$. Raw part geometry is defined by the 3D coordinates $(\mathrm{X})$ of reference coded targets obtained by the out of machine photogrammetry and fitting, expressed at the ideal part frame (OP). 


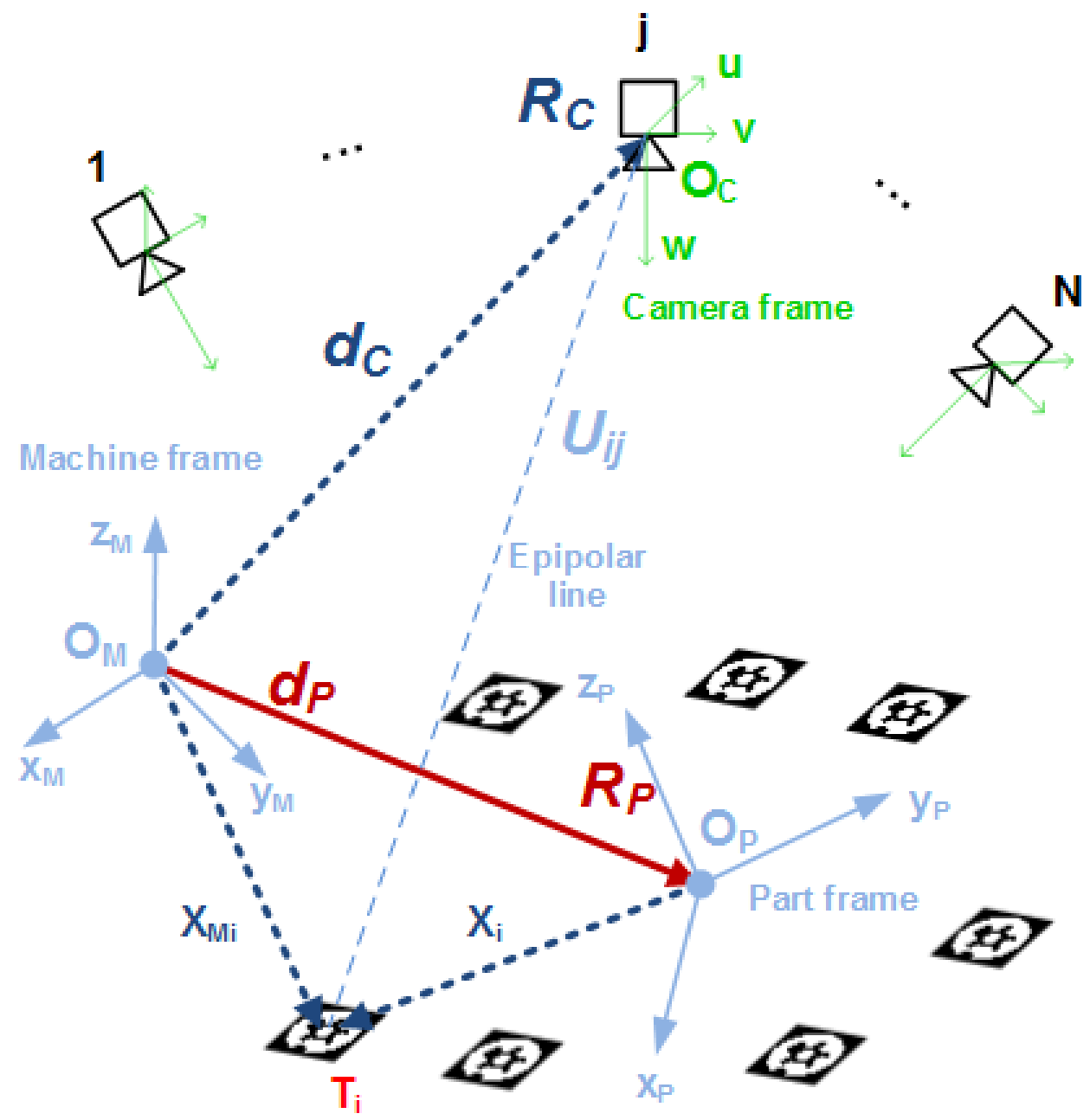

Figure 6. Measuring geometry of the OMM vision system by stereo-photogrammetry. A set of epipolar lines Uij given by detected Ti targets on images with known points of view $\left(\mathrm{d}_{\mathrm{C}}\right.$ and orientations $\mathrm{R}_{\mathrm{c}}$ camera extrinsic) at machine frame enables on machine raw part location and orientation $(6 \mathrm{D})$ measurement $\left(\mathrm{d}_{\mathrm{P}}\right.$ and $\left.\mathrm{R}_{\mathrm{P}}\right)$.

The process consists in solving the base where the point cloud with known $\mathrm{X}_{\mathrm{i}}$ coordinates is located with respect to the machine system $\mathrm{X}_{\mathrm{M}_{\mathrm{i}}}$ points.

$$
X_{M_{i}}=R_{P} X_{i}+d_{P}
$$

where the rotation matrix $R_{P}$ is composed by the multiplication of the 3 elementary rotation matrices through the so-called Euler angles $\alpha_{p}, \beta_{p}$ and $\gamma_{p}$. This transformation follows the $x, y$ and $\mathrm{z}$ rotation sequence

$$
\mathrm{R}_{\mathrm{P}}=\mathrm{R}_{\gamma} \mathrm{R}_{\beta} \mathrm{R}_{\alpha}
$$

On-machine measurement is conducted by taking a set of images to a set of reference targets $\left(T_{i}\right)$, each image taken from different CNC positions $\left(\mathrm{d}_{\mathrm{C}}\right)$ and orientations $\left(\mathrm{R}_{\mathrm{c}}\right)$. Each reference target $\left(\mathrm{X}_{\mathrm{i}}\right)$ observed in an image $\left(\mathrm{O}_{\mathrm{Cj}}\right)$ defines a so called epipolar line, that is to say, the direction at which that reference target lies in machine frame coordinates $\left(\mathrm{X}_{\mathrm{M}_{\mathrm{i}}}\right)$. With a minimum set of 3 linearly independent epipolar lines over a set of different reference targets, part location and orientation can be determined.

According to Equation (1), for a specific camera location $\left(\mathrm{d}_{\mathrm{C}}\right)$ and orientation $\left(\mathrm{R}_{\mathrm{c}}\right)$, target coordinates $\left(\mathrm{X}_{\mathrm{i}}\right)$ can be expressed into each camera frame $\left(\mathrm{O}_{\mathrm{Cj}}\right)$ as: 
(a) where $U_{i j}=\left[u_{i j} v_{i j} w_{i j}\right]^{T}$ and being $f$ the focal distance of the camera lens.

Each target 3D coordinate $\mathrm{U}_{\mathrm{ij}}$ can be then projected into the corresponding camera 2D image plane as $\mathrm{p}_{\mathrm{ij}}$ and $\mathrm{q}_{\mathrm{ij}}$ coordinates (Figure 7 ), following the widely assumed pin-hole model in machine vision [25] as:

$$
\left[\begin{array}{l}
p_{i j} \\
q_{i j}
\end{array}\right]=f\left[\begin{array}{l}
u_{i j} / w_{i j} \\
v_{i j} / w_{i j}
\end{array}\right]
$$

$$
\begin{gathered}
X_{M_{i}}=R_{C} U_{i j}+d_{C} \\
U_{i j}=R_{C}^{T}\left(X_{M_{i}}-d_{C}\right)
\end{gathered}
$$

This way, the former equations are combined into a single one as

$$
\mathrm{U}_{\mathrm{ij}}=\mathrm{R}_{\mathrm{C}}^{\mathrm{T}}\left(\mathrm{R}_{\mathrm{P}} \mathrm{X}_{\mathrm{i}}+\mathrm{d}_{\mathrm{P}}-\mathrm{d}_{\mathrm{C}}\right)
$$

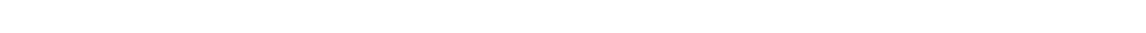

)

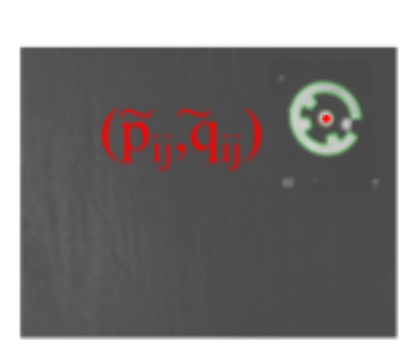

Residual errors $r_{p_{i j}}$ and $r_{q_{i j}}$ can be then defined for every target observed at an image (Figure

Figure 7. Target 2D detection and conic projection. (a) Example of reference target coordinate detection $\left(\tilde{p}_{i j}\right.$ and $\left.\tilde{q}_{i j}\right)$ at image plane. (b) Conic projection $\left(\mathrm{p}_{\mathrm{ij}}\right.$ and $\left.\mathrm{q}_{\mathrm{ij}}\right)$ into image plane of the 3D coordinate $\mathrm{X}_{\mathrm{ij}}$ corresponding to Ti optical target, with the corresponding projection error contribution $\left(\mathrm{r}_{\mathrm{ij}}\right.$ and $\mathrm{r}_{\mathrm{ijj}}$ ) to the joint residual minimization problem.

7) as the difference between detected target coordinates $\tilde{p}_{i j}$ and $\tilde{q}_{i j}$ and projected target coordinates $p_{i j}$ and $q_{i j}$, which directly depend on the part location $\left(d_{P}\right)$ and orientation $\left(R_{P}\right)$ to be solved. $A$ single joint residual vector $\vec{r}$ can be defined with the residuals $r_{p_{i j}}$ and $r_{q_{i j}}$ corresponding to the complete set of images of the on machine measurement according to the following structure:

$$
\overrightarrow{\mathrm{r}}=\left[\begin{array}{c}
\mathrm{r}_{1} \\
\vdots \\
\mathrm{r}_{\mathrm{N}}
\end{array}\right]
$$


where each $r_{j}$ vector contains the residual vectors of the error-projection for the detected markers $\left(m=\sum_{j=1}^{N} m_{j}\right)$ in the $j$ photograph:

$$
r_{j}=\left[\begin{array}{c}
r_{p_{1 j}} \\
r_{q_{1 j}} \\
\vdots \\
r_{p_{i j}} \\
r_{q_{i j}} \\
\vdots \\
r_{p_{m j}} \\
r_{q_{m j}}
\end{array}\right]=\left[\begin{array}{c}
p_{1 j}-\widetilde{p_{1 j}} \\
q_{1 j}-\widetilde{q_{1 j}} \\
\vdots \\
p_{i j}-\widetilde{p_{1 j}} \\
q_{i j}-\widetilde{q_{1 j}} \\
\vdots \\
p_{m j}-\widetilde{p_{m j}} \\
q_{m j}-\widetilde{q_{m j}}
\end{array}\right]
$$

In order to define the residual minimization problem, it is necessary to group all the parameters into a $\theta$ vector. In short, there are 6 parameters to solve

$$
\theta=\left[\begin{array}{llllll}
\alpha_{\mathrm{p}} & \beta_{\mathrm{P}} & \gamma_{\mathrm{P}} & \mathrm{X}_{\mathrm{P}} & \mathrm{Y}_{\mathrm{P}} & Z_{\mathrm{P}}
\end{array}\right]^{\mathrm{T}}
$$

The process is essentially the calculation of the optimal vector of parameters $\hat{\theta}$ which minimizes the objective function:

$$
\hat{\theta}=\arg \min _{\theta} \frac{1}{\mathrm{~N}}\|\overrightarrow{\mathrm{r}}\|^{2}
$$

The resolution is defined as the non-linear optimization problem solved by the Gauss-Newton method [26] which minimizes the residual vector $\|\vec{r}\|^{2}$ norm. These resolution methods are based on a first-order Taylor approximation of the objective function around a given point of the parameters vector $\hat{\theta}$. It is assumed that a small increase of the parameter vector $\Delta_{\theta}$ produces a change in the residual vector that can be well estimated by a lineal approximation as following

$$
\mathrm{r}\left(\theta+\Delta_{\theta}\right)=\mathrm{r}(\theta)+\mathrm{J}(\theta) \Delta_{\theta}+\theta\left(\Delta_{\theta}\right)
$$

The Jacobian J matrix contains the partial derivatives of each component of the residual vector respect to the parameters to optimize

$$
\mathrm{J}(\theta)=\left[\begin{array}{ccc}
\frac{\partial \mathrm{r}_{1}}{\partial \theta_{1}} & \cdots & \frac{\partial \mathrm{r}_{1}}{\partial \theta_{6}} \\
\vdots & \cdots & \vdots \\
\frac{\partial \mathrm{r}_{\mathrm{N}}}{\partial \theta_{1}} & \cdots & \frac{\partial \mathrm{r}_{\mathrm{N}}}{\partial \theta_{6}}
\end{array}\right]
$$

If all the columns of $\mathrm{J}$ are linearly independent, the Hessian matrix will be definite positive and, therefore, the $\mathrm{L}(\Delta \theta)$ will have a unique global minimum obtained from

$$
\mathrm{J}^{\mathrm{T}} \mathrm{J} \Delta_{\theta}=-\mathrm{J}^{\mathrm{T}} \mathrm{r}
$$

The core of the Gauss-Newton method is the resolution of the former equation, which is in fact, the system of Gauss's normal equations. For each iteration, the resolution of the system is followed by an update of the vector of parameters

$$
\theta \leftarrow \theta+\Delta_{\theta}
$$

Based there on, part location $\left(\mathrm{d}_{\mathrm{P}}\right)$ and orientation $\left(\mathrm{R}_{\mathrm{P}}\right)$ is defined as the non-linear optimization problem. Likewise, J matrix is composed by each $\mathrm{J}_{\mathrm{j}}$ jacobian of each image. 


$$
\mathrm{J}_{2 \mathrm{~m} \times 6}=\left[\begin{array}{c}
\mathrm{J}_{1} \\
\vdots \\
\mathrm{J}_{\mathrm{N}}
\end{array}\right]
$$

where $\mathrm{J}_{\mathrm{j}}$ contains the partial derivatives of the projection parameters respect to the $\alpha, \beta$ and $\Upsilon$ rotation angles:

$$
\left(\mathrm{J}_{\mathrm{j}}\right)_{2 \times 6}=\mathrm{D}_{\mathrm{P}} \mathrm{D}_{\mathrm{UP}_{\mathrm{P}}}
$$

Dp contains the derivatives respect to the projection parameters of each point in the image (see Equation (5)

$$
\left(D_{P}\right)_{2 \times 3}=f\left[\begin{array}{ccc}
\frac{1}{w_{i j}} & 0 & \frac{-u_{i j}}{w_{i j}^{2}} \\
0 & \frac{1}{w_{i j}} & \frac{-v_{i j}}{w_{i j}^{2}}
\end{array}\right]
$$

and $D_{U_{P}}$ refers to the partial derivatives from Equation (4) respect to $\alpha, \beta$ and $\Upsilon$ rotation angles.

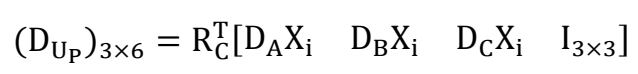

where $\mathrm{D}_{\mathrm{A}}$ is the partial derivative respect to $\alpha$ rotation angle,

$$
\mathrm{D}_{\mathrm{A}}=\frac{\partial \mathrm{R}_{\mathrm{P}}}{\partial \alpha}=\mathrm{R}_{\gamma} \mathrm{R}_{\beta} \frac{\mathrm{dR}_{\alpha}}{\mathrm{d} \alpha}
$$

$D_{B}$ respect to $\beta$ rotation angle,

$$
\mathrm{D}_{\mathrm{B}}=\frac{\partial \mathrm{R}_{\mathrm{P}}}{\partial \beta}=\mathrm{R}_{\gamma} \frac{\mathrm{dR}_{\beta}}{\mathrm{d} \beta} \mathrm{R}_{\alpha}
$$

and $\mathrm{D}_{\mathrm{C}}$ respect to $\Upsilon$ rotation angle.

$$
\mathrm{D}_{\mathrm{C}}=\frac{\partial \mathrm{R}_{\mathrm{P}}}{\partial \gamma}=\frac{\mathrm{dR}_{\gamma}}{\mathrm{d} \gamma} \mathrm{R}_{\beta} \mathrm{R}_{\alpha}
$$

As introduced in Section 2, a test part was then taken into a milling machine and properly aligned to be used as a precise reference object for the vision OMM performance evaluation (Figure 8). A spindle integrated contact probe was used in the machine as a reference for aligning the test part to the machine frame. Once the test part was aligned, a set of 10 consecutive measurements was performed by the vision OMM (Figure 8), at a measuring distance of $300 \mathrm{~mm}$ to each reference target, including system clamping-unclamping between each measurement set, with 2 images per target, to a total of 8 redundant images per set in order to solve part location and orientation (6D). 


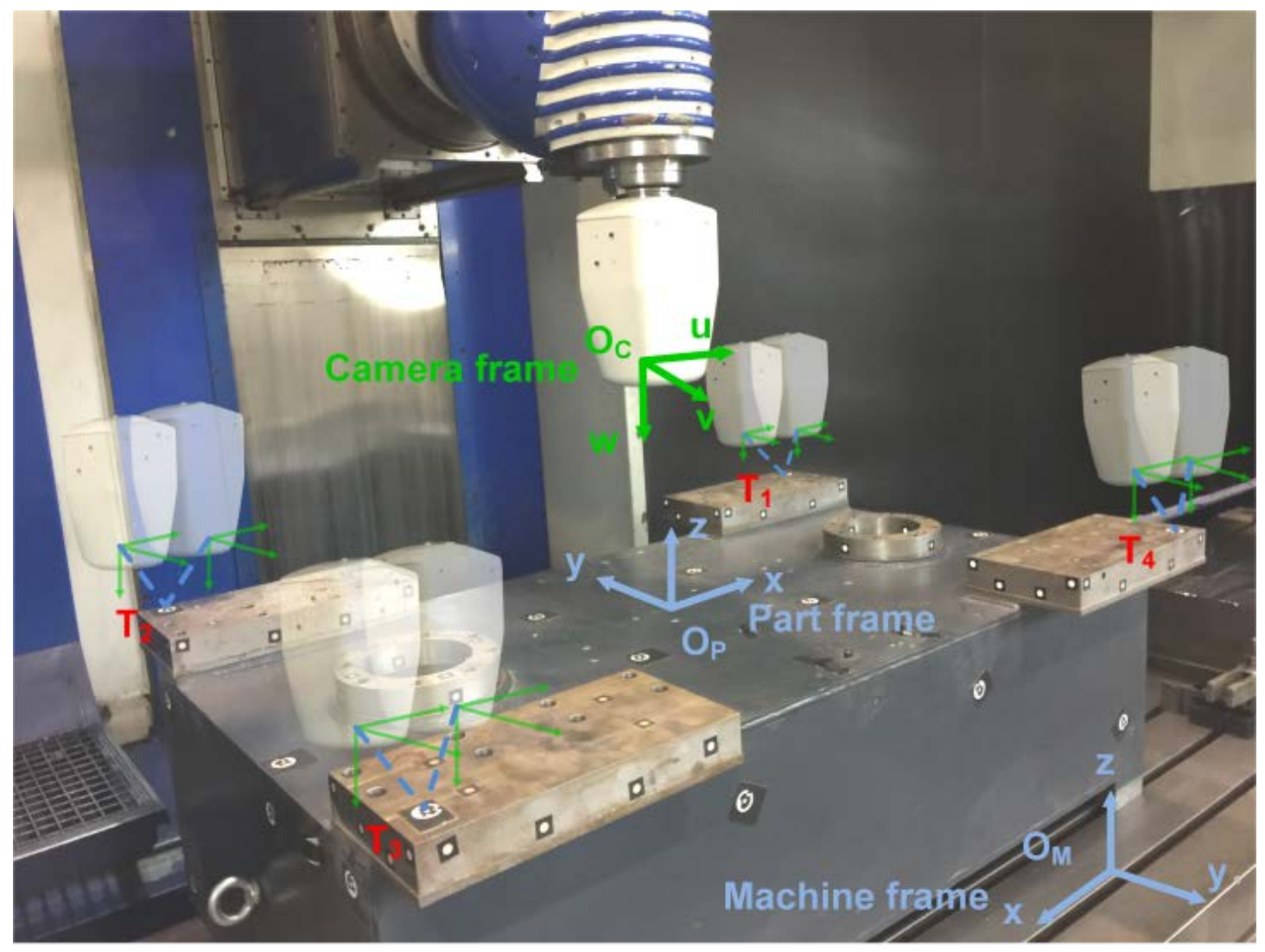

Figure 8. Testing scenario for the vision OMM self-calibration. Schematic view of the stereo-photogrammetric layout, with 2 images taken at each reference target placed at the XY plane, with the OMM measuring direction being $\mathrm{Z}$ axis.

Table 2 summarizes the repeatability results obtained for each measuring variable, having a common and constant OMM system calibration (see Table 1) and assuming that there is no misalignment between the OMM calibration frame (OCALIB) and the spindle frame (OCNC), given a constant $\gamma_{s}=0.0 \mathrm{~mm} / \mathrm{m}$ for all measurements. As expected, without a specific calibration every time the vision OMM system is clamped, $X_{p}$ and $Y_{p}$ machine coordinates (forming a perpendicular plane to $C$-axis, parallel to $Z_{p}$ axis), and $\gamma_{p}$ coordinate (twist around $Z_{p}$ axis) are directly affected by the coupling uncertainty around C-Axis $\left(\gamma_{\mathrm{s}}\right)$, ranging above $0.05 \mathrm{~mm}$ and $0.05 \mathrm{~mm} / \mathrm{m}$, respectively.

Table 2. Measurement repeatability $\boldsymbol{\sigma}(\boldsymbol{k}=2)$ for part location $\left(\boldsymbol{X}_{\boldsymbol{p}}, \boldsymbol{Y}_{\boldsymbol{p}}, \boldsymbol{Z}_{\boldsymbol{p}}\right.$ in mm $)$ and orientation $\left(\boldsymbol{R}_{\boldsymbol{P}}\right.$ rotation matrix expressed by Euler angles $\boldsymbol{\alpha}_{\boldsymbol{p}}, \boldsymbol{\beta}_{\boldsymbol{p}}, \boldsymbol{\gamma}_{\boldsymbol{p}}$, in $\mathrm{mm} / \mathrm{m}$ ).

\begin{tabular}{ccccccc}
\hline & $X_{p}$ & $Y_{p}$ & $Z_{p}$ & $\alpha_{p}$ & $\beta_{p}$ & $\gamma_{p}$ \\
\hline $6 D$ & 0.136 & 0.056 & 0.026 & 0.039 & 0.056 & 0.070 \\
\hline
\end{tabular}

\section{Clamping self-calibration}

In order to include self-calibration capabilities to the portable OMM vision system, coupling errors to be compensated have to be properly included into the measuring chain. Figure 9 shows the adopted geometry for considering the coupling positioning uncertainty around the C-axis $\left(\gamma_{\mathrm{s}}\right)$ for the ISO taper interface into the milling machine spindle. 


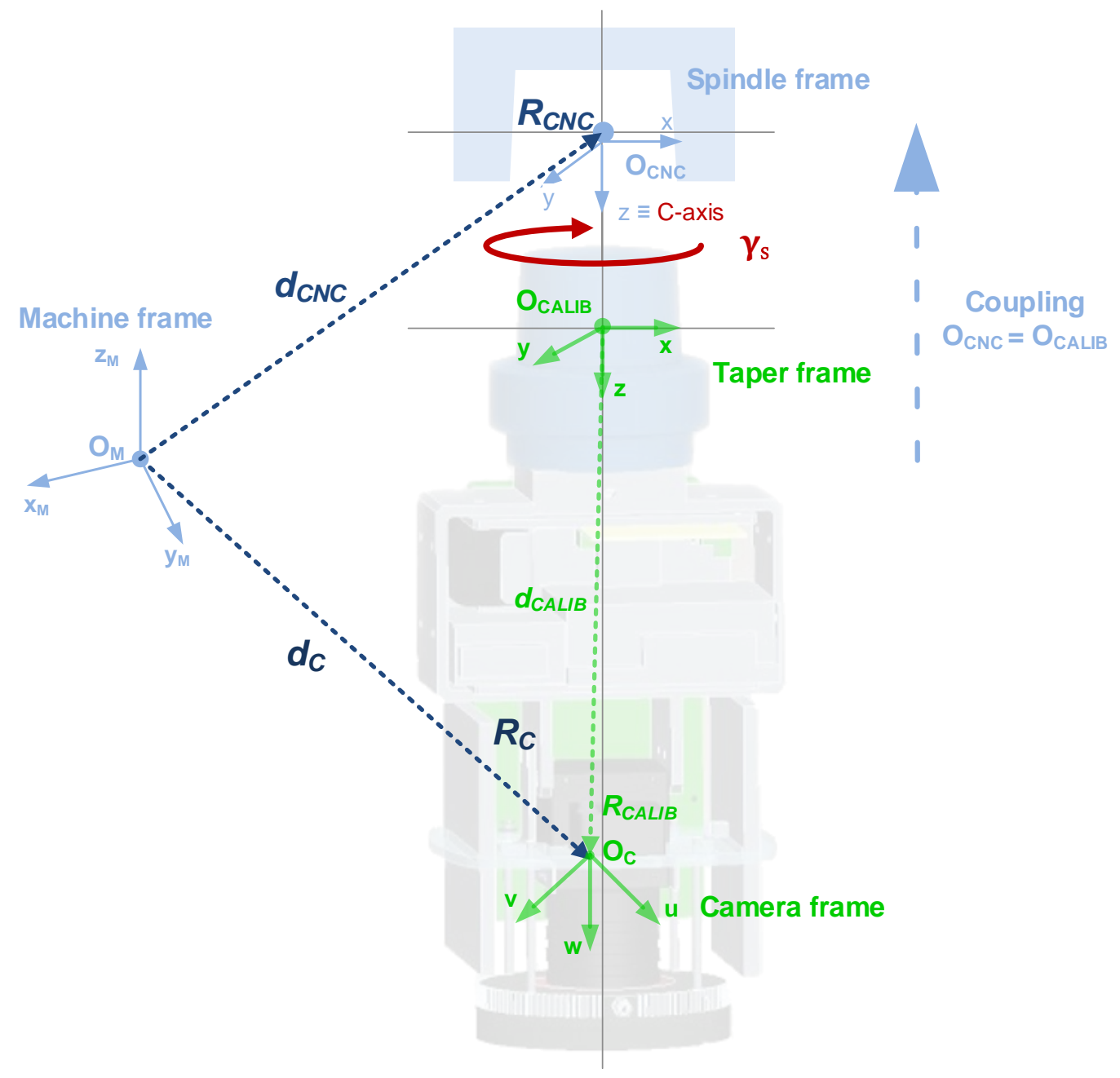

Figure 9. Coupling geometry of the vision OMM system, showing the complete chain for expressing camera extrinsic $\left(d_{C}\right.$ and $\left.R_{C}\right)$ at machine frame, given by spindle location and orientation by machine CNC ( $d_{C N C}$ and $\left.R_{C N C}\right)$, OMM calibration to taper joined frame $\left(d_{\text {Calib }}\right.$ and $\left.R_{\text {Calib }}\right)$, and coupling positioning ( $\gamma_{s}$ angle between spindle and OMM frame $\mathrm{z}$ axes).

Vision OMM geometry is defined as the camera frame (Oc) location $\left(d_{\text {calib }}\right)$ and orientation $\left(R_{\text {calib }}\right)$, obtained during on machine calibration. An error $\gamma_{s}$ is defined as the coupling orientation difference between the OMM positioning during calibration and during the actual measuring process. As a result, camera frame position $\left(d_{C}\right)$ and orientations $\left(R_{c}\right)$ can be expressed as:

$$
\begin{gathered}
d_{C}=R_{C N C} R_{S} d_{\text {Calib }}+d_{C N C} \\
R_{C}=R_{C N C} R_{S} R_{\text {Calib }}
\end{gathered}
$$

being $d_{c n c}$ and $R_{c n c}$ the CNC programmed spindle position and orientation for each image, respectively. And $R_{S}$ consist in a rotation matrix where the $\gamma_{S}$ is only taken into account:

$$
R_{S}\left(\gamma_{s}\right)=\left[\begin{array}{ccc}
\cos \left(\gamma_{s}\right) & \sin \left(\gamma_{s}\right) & 0 \\
-\sin \left(\gamma_{s}\right) & \cos \left(\gamma_{s}\right) & 0 \\
0 & 0 & 1
\end{array}\right]
$$

Accordingly, residual projection vector $\vec{r}$ can be expressed dependant to the $\gamma_{s}$ and included in the minimization problem. Therefore, in this case $\theta$ vector is composed by 7 parameters. 
358

359

360

$$
\theta=\left[\begin{array}{lllllll}
\alpha_{P} & \beta_{P} & \gamma_{P} & X_{P} & Y_{P} & Z_{P} & \gamma_{s}
\end{array}\right]^{T}
$$

Consequently, the Jacobian matrix J from Equation (14) has a new column

$$
J_{2 m \times 7}=\left[\begin{array}{c}
J_{1} \\
\vdots \\
J_{N}
\end{array}\right]
$$

because each $J_{j}$ from Equation (15) contains the partial derivatives which correspond to the spindle $\gamma$ rotation angle.

In short, $J_{j}$ is redefined as $J_{S}$ which includes the new column for spindle angle:

$$
\left(U_{S}\right)_{2 \times 7}=D_{P} D_{U_{S}}
$$

The partial derivatives respect to the projection parameters are not affected by the inclusion of this new term, so $D_{P}$ remains constant. Furthermore, since the $U_{i j}$ is modified, its partial derivatives are declared as follows

$$
\left(D_{U_{S}}\right)_{3 \times 7}=\left(R_{C N C} D_{S} R_{\text {Calib }}\right)^{T}\left[X_{i}-\left(R_{C N C} R_{S} d_{\text {Calib }}+d_{C N C}\right)\right]-\left(R_{C N C} R_{S} R_{\text {Calib }}\right)^{T}\left(R_{C N C} D_{S} d_{\text {Calib }}\right)
$$

where $D_{S}$ contains the partial derivatives associated to the $R_{S}$ rotation matrix with respect to the spindle $\gamma$ rotation angle:

$$
\left(D_{S}\left(\gamma_{s}\right)\right)_{3 \times 3}=\left[\begin{array}{ccc}
-\sin \left(\gamma_{s}\right) & \cos \left(\gamma_{s}\right) & 0 \\
-\cos \left(\gamma_{s}\right) & -\sin \left(\gamma_{s}\right) & 0 \\
0 & 0 & 1
\end{array}\right]
$$

As a result, OMM calibration $\left(d_{\text {calib }}, R_{\text {calib }}\right)$ is no longer required every time it is mounted into the spindle, and self-calibration can be accomplished along with determining part location $\left(d_{P}\right)$ and orientation $\left(R_{P}\right)$ if redundant measurement is conducted.

Table 3. Measurement repeatability $\boldsymbol{\sigma}(\boldsymbol{k}=2)$ for part location $\left(\boldsymbol{X}_{\boldsymbol{p}}, \boldsymbol{Y}_{\boldsymbol{p}}, \boldsymbol{Z}_{\boldsymbol{p}}\right.$ in mm) and orientation $\left(\boldsymbol{\alpha}_{\boldsymbol{p}}, \boldsymbol{\beta}_{\boldsymbol{p}}\right.$, $\boldsymbol{\gamma}_{\boldsymbol{p}}$, in $\mathrm{mm} / \mathrm{m}$,), along with coupling positioning angle $\left(\boldsymbol{\gamma}_{\boldsymbol{s}}\right.$, in $\left.\mathrm{mm} / \mathrm{m}\right)$.

\begin{tabular}{cccccccc}
\hline & $X_{p}$ & $Y_{p}$ & $Z_{p}$ & $\alpha_{p}$ & $\beta_{p}$ & $\gamma_{p}$ & $\gamma_{s}$ \\
\hline $6 D$ & 0.136 & 0.056 & 0.026 & 0.039 & 0.056 & 0.070 & -- \\
$7 D$ & 0.032 & 0.030 & 0.020 & 0.028 & 0.024 & 0.010 & 3.840 \\
Factor & 4.2 & 1.9 & 1.3 & 1.4 & 2.3 & 7.0 & --- \\
\hline
\end{tabular}

Table 3 summarizes the repeatability results obtained for each measuring variable in the testing scenario, comparing the results obtained with and without self-calibration (7D and 6D, respectively). With the self-calibration of coupling positioning uncertainty around the C-axis $\left(\gamma_{\mathrm{s}}\right)$, all measured values lay at a better and even repeatability figures, ranging below $0.04 \mathrm{~mm}$ and $0.03 \mathrm{~mm} / \mathrm{m}$ for part position and orientation measurement, respectively. Indeed, a coupling positioning repeatability of $3.84 \mathrm{~mm} / \mathrm{m} \sigma(\mathrm{k}=2)$ is measured and compensated for. Assuming a uniform distribution to the 
C-axis positioning stochastic process, it would correspond to a backlash of $6.65 \mathrm{~mm} / \mathrm{m}$ given by $\sqrt{3} \sigma(\mathrm{k}=2)$, close to the expected nominal value of $6,15 \mathrm{~mm} / \mathrm{m}$ (see Section 2$)$.

\section{Uncertainty estimation for the whole system}

Once the repeatability of the on-machine system has been evaluated and improved thanks to the self-calibration process presented (case 7D in Table 3), it is possible to assess the measurement uncertainty of the system. In order to evaluate the on-machine calibration and measurement process uncertainty, the test part is located back into the machine and properly aligned to the machine axes by gauging along all milled surfaces (Figure 8). Again, a set of 10 consecutive measurements was performed, with 2 images per reference marker (M1 to M4), to a total of redundant 8 images, but measuring distance was optimized from $300 \mathrm{~mm}$ to $150 \mathrm{~mm}$, so that the size of the reference target at image plane was maximized and image coordinate uncertainty was correspondingly minimized. Additionally, a set of 10 consecutive camera model calibrations were conducted in the CMM. In this scenario, for a constant measuring system and measurand geometries, two contributors are analyzed, $u_{i p}$ and $u_{i t .}$

- The former ( $\mathrm{u}_{\mathrm{ip}}$ ) corresponds to the contribution both due to the camera model calibration (Figure 5) and the part measuring process (Figure 6), integrating the joint contribution of gauging, machine positioning and image coordinate uncertainty during calibration and measuring processes. First, machine uncertainty in reference target coordinates is estimated, given by the standard deviation observed in the joint set of 100 calibration and measurements $(10 \times 10)$, estimated in $3.5 \mu \mathrm{m}$ for $X, 14.3 \mu \mathrm{m}$ for $\mathrm{Y}$ and $15.5 \mu \mathrm{m}$ for $\mathrm{Z}$. Since reference target coordinates determine the measured machine part location and orientation their uncertainty must be propagated to the whole working volume. A Monte Carlo analysis was carried out for that, incorporating as well the repeatability results for part location and orientation with calibration (case 7D in Table 3). Final results show maximum values for contributor $u_{i p}$ of $u_{i p, x}$ $=20.1 \mu \mathrm{m}, u_{i p, Y}=27.4 \mu \mathrm{m}$ and $u_{i p, Z}=23.5 \mu \mathrm{m}$ for $X, Y$ and $Z$ coordinates, respectively, in a scene size of $0.75 \mathrm{~m}^{3}(1.5 \mathrm{~m} \times 1 \mathrm{~m} \times 0.5 \mathrm{~m}$, see Figure 3 and 8$)$.

- The later (uit), accounts for the uncertainty contribution by the dimensional expansion of the workpiece due to temperature uncertainty during measurements. The maximum values of $\mathrm{u}_{\mathrm{it}}$ obtained for the working volume with a temperature variation of $\pm 1{ }^{\circ} \mathrm{C}$ were $9.5 \mu \mathrm{m}$ for $\mathrm{X}, 6.4$ $\mu \mathrm{m}$ for $\mathrm{Y}$ and $3.2 \mu \mathrm{m}$ for $\mathrm{Z}$.

From these contributors the expanded measurement uncertainty of the OMM system (Uomm) can be calculated by Equation (28), with a coverage factor $k=2$, for $X, Y$ and $Z$. Results are shown in Table 4.

$$
U_{\text {OMM }}=k \times \sqrt{u_{i p}^{2}+u_{i t}^{2}}
$$

Table 4. Main uncertainty contributors and OMM system estimated maximum expanded uncertainty $(\mathrm{k}=2)$ for the coordinates of any point in the scene volume.

\begin{tabular}{|llll|}
\hline & $X[\mu m]$ & $Y[\mu m]$ & $Z[\mu m]$ \\
\hline$u_{i p}$ & 20.1 & 27.4 & 23.5 \\
$u_{i t}$ & 9.5 & 6.4 & 3.2 \\
\hline$U_{\text {омм }}(k=2)$ & 44.5 & 56.3 & 47.4 \\
\hline
\end{tabular}

If the whole process is analyzed and both, out-of-machine and on-machine measuring processes are put together, the total uncertainty ( $U_{\text {total }}$ ) can be then calculated by Equation (29) (with $k=2$ ) for $X$, $\mathrm{Y}$ and $\mathrm{Z}$. As mentioned in Section 2, part geometry given by optical target 3D coordinates was measured by photogrammetry and fitted to the nominal CAD geometry by the out-of-machine measuring system (Figure 1). This process results in an additional contributor (uout). Joint uncertainty evaluation of the out-of-machine measuring and fitting processes, including the 
non-coded targets, was evaluated according to the Length Measurement Error (LME) evaluation guideline by VDI 2634 [27]. Contributions due to the scale factor and temperature changes were also included in the analysis, resulting in values around $70 \mu \mathrm{m}$ for contributor uout for the $\mathrm{X}, \mathrm{Y}$ and $\mathrm{Z}$ coordinates of the photogrammetric targets at the test part as shown in Table 5.

$$
U_{\text {total }}=k \times \sqrt{u_{\text {out }}^{2}+u_{i p}^{2}+u_{i t}^{2}}
$$

Table 5 summarizes the set of analyzed uncertainty contributors, and a total uncertainty of $\mathrm{U}_{\text {total }, \mathrm{X}}=148.5 \mu \mathrm{m} ; \mathrm{U}_{\text {total }, \mathrm{Y}}=151.8 \mu \mathrm{m} ; \mathrm{U}_{\text {total }, \mathrm{Z}}=148.4 \mu \mathrm{m}$ is estimated for the machine coordinates of non-coded targets characterizing part geometry in a scene size of $0.75 \mathrm{~m}^{3}(1.5 \mathrm{~m} \mathrm{x} 1 \mathrm{~m} \times 0.5 \mathrm{~m}$, see Figure 3 and 8). This uncertainty is one order of magnitude smaller than the one obtained in the previous work [3] where no specific self-calibration capability was included in the OMM.

Table 5. Main uncertainty contributors and total (out-of-machine plus on-machine measuring systems) estimated maximum expanded uncertainty $(k=2)$ for the coordinates of any point in the scene.

\begin{tabular}{|llll|}
\hline & $X[\mu \mathrm{m}]$ & $\Upsilon[\mu \mathrm{m}]$ & $Z[\mu \mathrm{m}]$ \\
\hline uout $_{\text {uip }}$ & 70.9 & 70.5 & 70.3 \\
$u_{\text {it }}$ & 20.1 & 27.4 & 23.5 \\
\hline$U_{\text {total }}(k=2)$ & 9.5 & 6.4 & 3.2 \\
\hline
\end{tabular}

In order to evaluate the estimated total uncertainty in the test-bench scenario, a spindle integrated contact probe was used for gauging a minimum set of 10 non coded targets distributed in 3 directions and at extreme and opposite surfaces of the test part. Each target was gauged according to the contact probe tool offset given by the OMM raw part location and its expected location according to its ideal 3D coordinates given by the out-of-machine photogrammetric and fitting process. A gauging process was conducted after each OMM measurement of the set of 10 described in Section 3.2 for measurement repeatability evaluation, and $10 \times 10$ probing errors were observed between the ideal gauging coordinate and actual no coded target placement in machine coordinates. A probing repeatability of $0.10 \mathrm{~mm}$ was observed, homogeneously distributed in three $\mathrm{X}, \mathrm{Y}$ and $\mathrm{Z}$ gauging directions, given by the $\sigma(k=2)$ of the probing error distribution, with all probing errors in all surfaces being below $+/-0.15 \mathrm{~mm}$. An overestimation at Table 5 can be observed, where total uncertainty estimations range at $0.15 \mathrm{~mm}\left(\mathrm{U}_{\text {total }}(\mathrm{k}=2)\right), 0.05 \mathrm{~mm}$ above the $0.10 \mathrm{~mm}(\sigma(k=2))$ resulting from the probing error evaluation. The main contribution is given by the out of machine portable photogrammetry process. According to LME evaluation results reported in literature [28], typical LME errors could also be estimated as $50 \mu m+20 \mu \mathrm{m} / \mathrm{m}$ for portable photogrammetry, which will result in an uncertainty estimation ( $u_{\text {out }}$ ) of $40,4 \mu \mathrm{m}$ for $1 \mathrm{~m}$ long scene in the test-bench scenario, given that $u_{\text {out }}={ }_{L M E} / \sqrt{3}$, pointing out a possible uncertainty overestimation in the LME error evaluation conducted in the present work following the VDI2634 guideline, where LME errors up to $121,4 \mu \mathrm{m}$ were observed in the worst case scenario.

Finally, the system has been evaluated in an industrial scenario (Figure 10) demonstrating fast and precise raw part geometry control and on machine alignment guided by the self-calibrated vision OMM system presented in this paper. Four representative part models were adopted for the evaluation, all of them included in a maximum prismatic working volume of $10 \mathrm{~m} \times 3 \mathrm{~m} \times 5 \mathrm{~m}$, according to their first machining set-up in machine $\mathrm{X}, \mathrm{Y}$, and $\mathrm{Z}$ axes, with a maximum scene volume ranging $150 \mathrm{~m}^{3}$. 


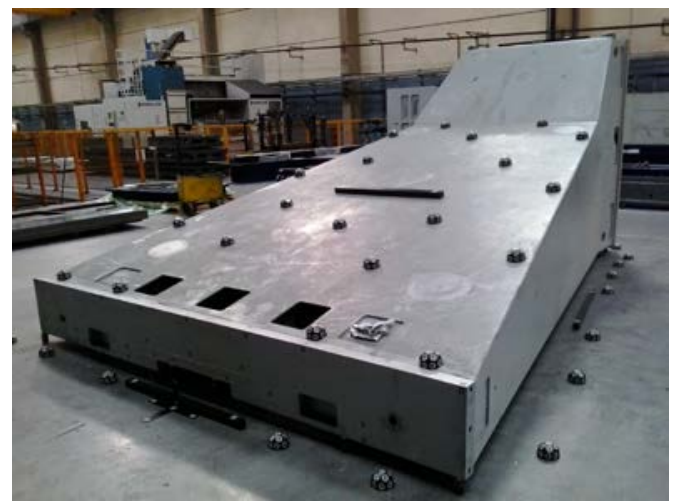

(a)

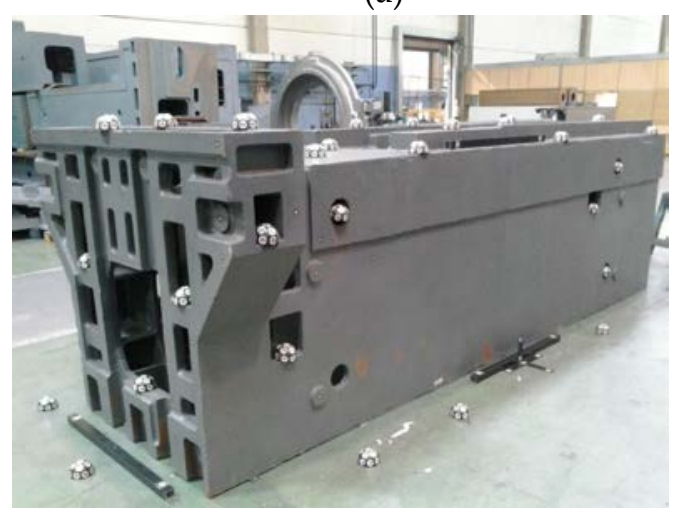

(c)

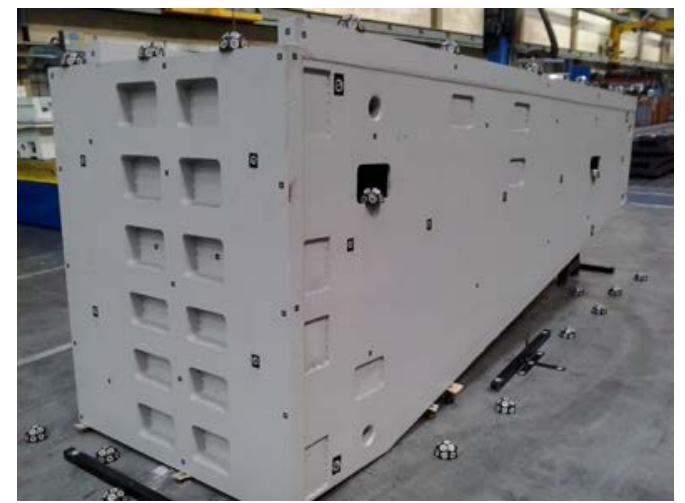

(b)

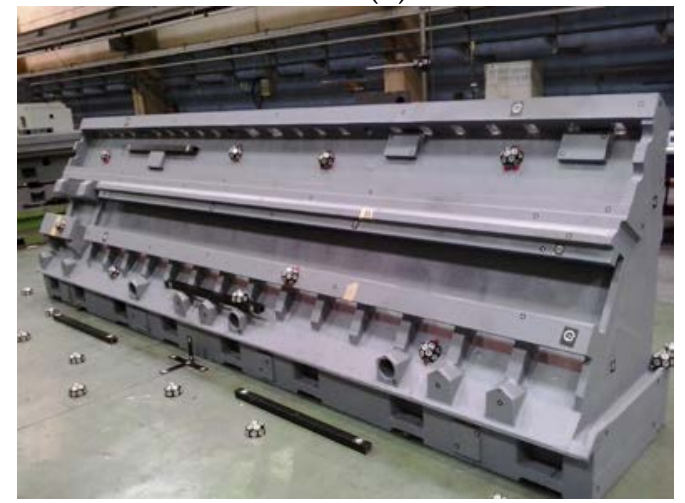

(d)

Figure 10. Evaluation test of the system at end-user (Goimek, Elgoibar, Spain) in Soraluce milling machines. 4 components are adopted for evaluation under a maximum working volume of $10 \mathrm{~m} \times 3$ $\mathrm{m} \times 5 \mathrm{~m}$. (a) Milling machine structural gantry (b) Grinding machine vertical column. (c) Milling machine travelling column. (d) Lathe bed. Reference targets placed at XZ plane for all cases, with $\mathrm{OMM}$ measuring direction being $\mathrm{Y}$ axis.

The out-of-machine photogrammetry and fitting process took an overall time of 2 hours per part, determining the optimal 3D coordinates of 4 reference coded target per part. Four reference coded targets were placed at XZ plane, located at extreme raw part positions. Reference coded targets were measured in the machine by the OMM integrating self-calibration capability, resembling the same measuring strategy as described previously, with 2 images per target up to a total of 8 images from different machine positions. Raw part was then aligned manually by the machine operator by adjusting the corresponding fixturing tools, guided by the OMM measuring of raw part orientation $\left(\alpha_{\mathrm{p}}, \beta_{\mathrm{p}}, \gamma_{\mathrm{p}}\right.$, in $\left.\mathrm{mm} / \mathrm{m}\right)$. A set of 10 consecutive measurements was performed by the vision OMM following same approach as shown in Figure 8, but being Y machine axis the OMM measuring direction since reference targets are located at XZ plane, with a measuring distance of 150 $\mathrm{mm}$ to each reference target, including system clamping-unclamping between each measurement set. Same image detection quality was expected both in laboratory and industrial scenarios, given by the active LED illumination integrated by the vision OMM, same measuring distance and reference target size. Indeed, similar repeatability figures were observed in the industrial scenario for raw part location (dp) ranging $0.02 \mathrm{~mm}(\mathrm{k}=2)$. Correspondingly, a reduction of one order of magnitude was observed in raw part orientation measurement $(\mathrm{Rp})$, with angle measurement repeatability ranging below $0.005 \mathrm{~mm}(\mathrm{k}=2)$, proportional to the larger relative distance between measured reference targets (at XZ plane, $10 \mathrm{~m} \times 3 \mathrm{~m}$ ) comparing to the test bench scenario ( $\mathrm{XY}$ plane, $1.5 \mathrm{~m} \mathrm{x} 1 \mathrm{~m}$ ),

Again, assuming a constant measuring system and measurand geometries, three contributors are estimated for the industrial scenario, uip, uit, and uout:

- Assuming a constant image detection uncertainty in both scenarios, laboratory $(1.5 \mathrm{~m} \mathrm{x} 1 \mathrm{~m} \mathrm{x}$ $0.5 \mathrm{~m})$ and industrial $(10 \mathrm{~m} \times 3 \mathrm{~m} \times 5 \mathrm{~m})$, and given a similar measuring geometry for measuring each reference target, measurement uncertainty on reference target machine 
coordinates can be assumed independent to scene size, previously estimated in for the test bench scenario. $3.5 \mu \mathrm{m}$ for $X, \mu \mathrm{m}$ for $\mathrm{Y} 15.5$ and $14.3 \mu \mathrm{m}$ for $Z$. Note that estimations for $\mathrm{Y}$ and $Z$ are correspondingly interchanged due to the change of OMM measuring direction from $Z$ in the test bench scenario (Figure 8) to $\mathrm{Y}$ in the industrial scenario. A Montecarlo analysis was conducted to propagate reference target uncertainty in the industrial scene volume of $10 \mathrm{~m} \times 3$ $\mathrm{m} \times 5 \mathrm{~m}$, showing maximum values for contributor $u_{i p}$ of $u_{i p, X}=57.6 \mu \mathrm{m}, u_{i p, Y}=140.2 \mu \mathrm{m}$ and $u_{i p, Z}=134.9 \mu \mathrm{m}$ for $\mathrm{X}, \mathrm{Y}$ and $\mathrm{Z}$ coordinates, respectively.

- Maximum temperature uncertainty during measurement was $\pm 1 \stackrel{\circ}{\circ} \mathrm{C}$ for the industrial scenario, resulting in an uncertainty contribution by dimensional expansion ( $\mathrm{u}_{\mathrm{it}}$ ) of the workpiece of $64.0 \mu \mathrm{m}$ for $X, 19.2 \mu \mathrm{m}$ for $\mathrm{Y}$ and $32.0 \mu \mathrm{m}$ for $\mathrm{Z}$.

- Uncertainty contribution due to out of machine photogrammetry (uout) is estimated according to [28] for the $10 \mathrm{~m} \times 3 \mathrm{~m} \times 5 \mathrm{~m}$ scene volume, resulting in $144.3 \mu \mathrm{m}$ for $\mathrm{X}, 89.3 \mu \mathrm{m}$ for $\mathrm{Y}$ and $112.4 \mu \mathrm{m}$ for $\mathrm{Z}$, given the scale dependent LME error contributor of $20 \mu \mathrm{m} / \mathrm{m}$.

Table 5 summarizes the set of estimated contributors for the industrial scenario, and a total uncertainty of Utotal, $\mathrm{X}=336.1 \mu \mathrm{m}$; Utotal, $\mathrm{Y}=334.6 \mu \mathrm{m}$; Utotal, $\mathrm{Z}=356.9 \mu \mathrm{m}$ is estimated for the machine coordinates of non-coded targets characterizing part geometry in a scene size of $150 \mathrm{~m} 3$ (10 $\mathrm{m} \times 3 \mathrm{~m} \times 5 \mathrm{~m}$, see Figure 10).

Table 6. Main uncertainty contributors and total uncertainty estimation in the industrial scenario for the

\begin{tabular}{|llll|}
\multicolumn{4}{c}{ machine coordinates of any point at raw part surfaces. } \\
\hline & $X[\mu \mathrm{m}]$ & $Y[\mu \mathrm{m}]$ & $Z[\mu \mathrm{m}]$ \\
\hline$u_{\text {out }}$ & 144.3 & 89.3 & 112.4 \\
$u_{\text {ip }}$ & 57.6 & 140.2 & 134.9 \\
$u_{\text {it }}$ & 64.0 & 19.2 & 32.0 \\
\hline$U_{\text {total }}(k=2)$ & 336.1 & 334.6 & 356.9 \\
\hline
\end{tabular}

In order to evaluate the estimated total uncertainty, the same probing error evaluation methodology was adopted on the four part models under study (Figure 10), as previously described for the laboratory test bench. In this case, a probing repeatability of $0.34 \mathrm{~mm}$ was observed, with a difference ranging $0.01 \mathrm{~mm}$ to the estimated figures in Table 6. Again, homogeneously distributed probing errors were observed in three $\mathrm{X}, \mathrm{Y}$ and $\mathrm{Z}$ gauging directions, assuming $\sigma(k=2)$ for the probing error distribution, with all probing errors in all surfaces ranging below $+/-0.50 \mathrm{~mm}$, demonstrating the adequate accuracy of the system for large raw part alignment processes with tight overstock allowances.

The capability of the measurement process can be determined in accordance with Berndt's principle ("golden rule" of metrology) $[29,30]$ that states that the measurement uncertainty shall be less than $20 \%$ of the tolerance. In the presented case the tolerance is established in $\pm 1 \mathrm{~mm}$, as a tight overstock allowance to be controlled in up to $10 \mathrm{~m}$ long raw parts. According to the results shown in Table 6 , the ratio U/T shows values of $17 \%$ for both $\mathrm{X}$ and $\mathrm{Y}$ and $18 \%$ for $\mathrm{Z}$. Therefore, the measurement process can be considered capable for the required tolerance in accordance with Berndt's principle.

Along with the demonstrated accuracy due to developed self-calibration capability, under the analyzed industrial scenario, comparing to the conventional manual means for on machine raw part alignment by using contact probes, the OMM vision system has shown the potential of reducing alignment time from up to 1 hour to less than $15 \mathrm{~min}$, as a result of the fast and efficient measurement by vision stereo-photogrammetry of a minimum set of optical reference targets. Additional benefits of the proposed system can be pointed out, such as process cost savings since enables the application of a common alignment methodology in production regardless to the part geometry since reference targets can be similarly place for different part models, digital traceability of adopted raw part location and orientation prior to each machining, and increased reliability since alignment process brings lower dependence to machine operator skills. 


\section{Conclusions}

A self-calibration technique by using redundant information of on-machine measurements by machine vision has been presented. It has been applied to a machine vision system directly mounted in the machine tool spindle with an ISO taper. The out-of-machine calibration process for the camera model extrinsic and intrinsic parameters and the OMM mathematical model have been presented. The self-calibration technique developed to avoid the calibration of the system every time it is mounted into the spindle has been described. The system has been tested on a milling machine used as test scenario and evaluated on other milling machine in an industrial scenario. The results show that the application of this technique reduces the uncertainty due to the angular placement of the taper with no need of extra anchoring or further calibration of the probe with respect to the spindle. It is based on the integrated resolution of the position and orientation of the part together with the placement uncertainty.

By using it, the measurement repeatability has been improved for the portable vision OMM, ranging below $0.05 \mathrm{~mm}$ and $0.05 \mathrm{~mm} / \mathrm{m}$ for part position and orientation measurement in laboratory conditions (working volume $1.5 \mathrm{~m} \mathrm{x} 1 \mathrm{~m} \times 0.5 \mathrm{~m}$ ), respectively. The final measurement uncertainty has been improved from the range of $1 \mathrm{~mm}$, that the system presented in laboratory conditions without the specific self-calibration here shown [3], to the range of $0.15 \mathrm{~mm}$. Under industrial conditions (working volume $10 \mathrm{~m} \times 3 \mathrm{~m} \times 5 \mathrm{~m}$ ) the measurement process showed an uncertainty ranging 0.3-0.4 mm, assuring its performance for the in-machine alignment of large raw parts with tight overstock allowances of up to $\pm 1 \mathrm{~mm}$.

\section{Acknowledgments}

The authors wish to thank Soraluce S.Coop machine tool builder and Goimek S.Coop machining shop from Danobatgroup for their support for this research. Moreover, the authors wish to thank the anonymous reviewers for their valuable advice, which has led to an improvement of the article.

\section{References}

1. Uriarte, L; Zatarain, M; Axinte, D; Yagüe-Fabra, J; Ihlenfeldt, S; Eguia, J; Olarra, A. Machine tools for large parts. CIRP Annals - Manufacturing Technology 2013, 62(2), 731-750.

2. Schmitt, RH; Peterek, M; Morse, E; Knapp, W; Galetto, M; Härtig, F; Goch, G; Hughes, B; Forbes, A; Estler, WT. Advances in Large-Scale Metrology - Review and future trends. CIRP Annals - Manufacturing Technology 2016, 65(2), 643-665.

3. Zatarain, M; Mendikute, A; Inziarte, I. Raw part characterisation and automated alignment by means of a photogrammetric approach. CIRP Annals - Manufacturing Technology 2012, 61(1), 383-386.

4. Guiassa, R; Mayer, JRR. Predictive compliance based model for compensation in multi-pass milling by on-machine probing. CIRP Annals - Manufacturing Technology 2011, 60(1), 391-394.

5. Schwenke, H; Knapp, W; Haitjema, H; Weckenmann, A; Schmitt, R; Delbressine, F. Geometric Error Measurement and Compensation of Machines. Manufacturing Technology 2008, 57(2), 660-675.

6. Yagüe, JA; Velázquez, J; Albajez, JA; Aguilar, Jj; Lope, MA; Santolaria, J. Development and calibration of self-centring probes for assessing geometrical errors of machines. Measurement Science and Technology 2009, 20(11), 115103

7. Mayr, J; Jedrzejewski, J; Uhlmann, E; Alkan, Donmez M; Knapp, W; Härtig F, et al. Thermal issues in machine tools. CIRP Annals - Manufacturing Technology 2012, 61(2), 771-791.

8. ISO 230-10:2016, Test code for machine tools -- Part 10: Determination of the measuring performance of probing systems of numerically controlled machine tools.

9. Jankowski, M; Wozniak, A. Mechanical model of errors of probes for numerical controlled machine tools. Measurement 2016, 77, 317-326.

10. Yagüe, JA; Albajez, JA; Velázquez, J; Aguilar, JJ. A new out-of-machine calibration technique for passive contact analog probes. Measurement 2009, 42(3), 346-357.

11. Rivin, EI; Agapiou, J; Brecher, C; Clewett, M; Erickson, R; Huston, F, et al. Tooling Structure: Interface between Cutting Edge and Machine Tool. CIRP Annals - Manufacturing Technology 2000, 49(2), 591-634. 
12. Abele, E; Altintas, Y; Brecher, C. Machine tool spindle units. CIRP Annals - Manufacturing Technology 2010, 59(2), 781-802.

13. Neugebauer, R; Denkena, B; Wegener K. Mechatronic Systems for Machine Tools. CIRP Annals Manufacturing Technology 2007, 56(2), 657-686.

14. Leoni Advintec TCP. Available online: www.leoni-industrial-solutions.com/en/products-services/calibration-of-robotic-tools-fixtures/

15. De Ma, S. A self-calibration technique for active vision systems. IEEE Transactions on Robotics and Automation 1996, 12(1), 114-120.

16. Motta, JMST; de Carvalho, GC; McMaster RS. Robot calibration using a 3D vision-based measurement system with a single camera. Robotics and Computer-Integrated Manufacturing 2001, 17(6), 487-297.

17. Sharp, CS; Shakernia; O, Sastry, SS. A vision system for landing an unmanned aerial vehicle. IEEE International Conference on Robotics and Automation 2001, 2, 1720-1727.

18. Babapour, H; Mokhtarzade, M; Zoej, M.J.V. Self-calibration of digital aerial camera using combined orthogonal models. ISPRS Journal of Photogrammetry and Remote Sensing 2016, 117:29-39.

19. You, S; Neumann, U. Fusion of vision and gyro tracking for robust augmented reality registration. IEEE Proceedings on Virtual Reality 2001, 71-78.

20. Ali, S.H.R. The Influence of Fitting Algorithm and Scanning Speed on Roundness Error for $50 \mathrm{~mm}$ Standard Ring Measurement Using CMM. Metrology \& Measurement Systems, Polish Academy of Sciences, Warsaw, Poland, 2008, 15(1), 31-53.

21. Ali, S.H.R. Probing System Characteristics in Coordinate Metrology. Measurement Science Review, Journal of the Institute of Measurement Science, Slovak Academy of Sciences, Slovakia, 2010, 10(4), 120-129.

22. Ali, S.H.R.; Mohamd, O.M. Dimensional and Geometrical Form Accuracy of Circular Pockets Manufactured for Aluminum, Copper and Steel Materials on CNC Milling Machine using CMM. International Journal of Engineering Research in Africa, 2015, 17, 64-73.

23. Lu, X; Rao, N; Usman, I. Six-axis position measurement system for levitated motion stages. CIRP Annals Manufacturing Technology 2013, 62(1), 507-510.

24. Brown DC (1966) Decentering distortion of lenses, Photometric Engineering, 32/3:444-462.

25. Hartley, R; Zisserman, A. Multiple View Geometry in Computer Vision, Cambridge University Press, Cambridge, 2003.

26. Madsen, K; Nielsen, HB; Tingle, O. Methods for non-linear least squares problems, 2nd ed., 2004.

27. VDI. VDI/VDE 2634: Optical 3D measuring systems - part 1, VDI/VDE Guide Line, Beuth, Berlin, 2000.

28. Luhmann, T; Robson, S; Kyle, S; Harley, I. Close range photogrammetry. Whittles Publishing, Dunbeath 2011.

29. Berndt G, Hultzsch E, Weinhold H. Funktionstoleranz und Messunsicherheit. Wissenschaftliche Zeitschrift der Technischen Universität Dresden 1968, 17(2), 465-471.

30. Sładek, J A. Coordinate Metrology: Accuracy of Systems and Measurements. Springer-Verlag Berlin Heidelberg 2016. 